\title{
Correction to: Ant-mediated ecosystem processes are driven by trophic community structure but mainly by the environment
}

\author{
Alex Salas-Lopez ${ }^{1} \cdot$ Mickal Houadria $^{2}$ (D) $\cdot$ Florian Menzel $^{2} \cdot$ Jérôme Orivel $^{1}$
}

Published online: 30 August 2020

(c) Springer-Verlag GmbH Germany, part of Springer Nature 2020

\section{Correction to: Oecologia (2017) 183:249-261 \\ https://doi.org/10.1007/s00442-016-3741-z}

Unfortunately, the given and family names of author "Mickal Houadria" was incorrectly published in the original article and is corrected here by this erratum. In addition, the ORCID ID: http://orcid.org/0000-0002-8937-2139 of author Mickal Houadria is updated.

Alex Salas-Lopez

alex.salaslopez@gmail.com

1 CNRS, UMR Ecologie de Forêts de Guyane,

AgroParisTech, CIRAD, INRA, Université de Guyane,

Université des Antilles, Campus agronomique, BP 316,

97379 Kourou Cedex, France

2 Department of Evolutionary Biology, Institute of Zoology,

University of Mainz, Mainz, Germany 